Polymer Journal, Vol. 39, No. 5, pp. 478-487 (2007)

(C)2007 The Society of Polymer Science, Japan

\title{
Effect of Structure of Bridging Group on Curing and Properties of Bisphenol-A Based Novolac Epoxy Resins
}

\author{
Guoyuan PAn, ${ }^{1}$ Zhongjie Du, ${ }^{1}$ Chen Zhang,${ }^{1}$ Congju LI, ${ }^{2}$ \\ Xiaoping YANG, ${ }^{1}$ and Hangquan $\mathrm{LI}^{1, \dagger}$ \\ ${ }^{1}$ The Key Laboratory of Beijing City on Preparation and Processing of Novel Polymer Materials, \\ Beijing University of Chemical Technology, Beijing 100029, P. R. China \\ ${ }^{2}$ Beijing Key Laboratory of Clothing Material $R \& D$ and Assessment, \\ Beijing Institute of Clothing Technology, Beijing 100029, P. R. China
}

(Received December 22, 2006; Accepted February 28, 2007; Published April 9, 2007)

\begin{abstract}
Three bisphenol-A based novolac epoxy resins with different bridging groups: methylene, methinephenyl and methine-naphthyl, respectively, between bisphenol-A phenyl rings were prepared to study the effect of structure of bridging group on curing and properties of the epoxy resins. The structures of the obtained epoxy resins were characterized using FT-IR and ${ }^{1} \mathrm{H}$ NMR spectra, the molecular weight and polydispersity index were determined using GPC. The effect of bridging groups on the curing kinetics, thermal mechanical properties, thermal stability, and moisture resistance of the synthesized epoxy resins cured with 4,4'-diaminodiphenyl sulphone (DDS) were investigated by dynamic differential scanning calorimetry, dynamic mechanical analysis, thermogravimetric analysis, X-ray diffraction and moisture absorption measurement. It was concluded that the methylene-bridged epoxy resin possessed the highest curing reaction reactivity toward DDS and the methine-naphthyl-bridged epoxy network possessed the highest storage modulus, glass transition temperatures, thermal stability, and moisture resistance.
\end{abstract}

[doi:10.1295/polymj.PJ2006201]

KEY WORDS Bisphenol-A / 1-Naphthaldehyde / Benzaldehyde / Bridging Group /

Epoxy resin has been utilized in many applications such as surface coatings, structural adhesives, printed circuit board, insulation materials for electronic devices, and advanced composites matrices due to its good thermal and dimensional stability, excellent chemical and corrosion resistance, and superior mechanical and electrical properties, in addition to ease of handling and processabilities. However, in hightech applications lower thermal expansion, higher toughness, better heat and moisture resistance were required. ${ }^{1}$ For this reason, much work has been continuously directed toward improving their thermal and physical properties by modifications of epoxy resins, in both backbone and pendant groups. ${ }^{2-5}$

Several approaches were adopted to enhance the heat resistance of epoxy resins with increasing crosslink density or introducing bulky structures such as biphenyl or naphthalene. ${ }^{6-8}$ The introduction of naphthalene moiety is expected to greatly improve the thermal property and moisture resistance owing to its excellent rigidity, facile packing of molecules and significant degree of hydrophobicity. ${ }^{9-14}$ Many studies reported that epoxy resin showed remarkably higher glass transition temperature $\left(T_{\mathrm{g}}\right)$, higher thermal stability, higher flexural modulus, better moisture resistance, lower coefficient of thermal expansion when stiff naphthalene was inserted or appended by chemical modification. ${ }^{15-18}$ In order to design and develop more novel epoxy resins with higher thermal and mechanical properties to meet the application need, the deeply understanding the effect of the molecular structure of materials on curing behavior, chemical and physical properties of epoxy resin was increasingly more important, because it can predict the end product properties of the new materials and provide a guide for the development process and speed up the development cycle. Varley et al. utilized the relationship between the structure and properties as a tool, and formulated high-performance epoxyamine networks. ${ }^{19,20}$ Investigation into the effect of starting materials with analogous molecular structure on properties of the resulting polymer network constituted an important method to understand the mechanism, especially the effect of the molecular structure with bridging group on the properties of epoxy network. ${ }^{21,22}$ What's more, some researchers reported the effect of bridging group of curing agent on the curing behavior and properties of epoxy resin system. ${ }^{23,24}$ The results also showed that the reactivity and physical properties of the epoxy-amine system depended on the structure of the aromatic amines. However, so far there have been no reports on the effect of bridging groups on the curing kinetics and properties of modified bisphenol-A epoxy resins.

${ }^{\dagger}$ To whom correspondence should be addressed (Tel: +81-010-64445339, Fax: +81-42-64428804, E-mail: Duzj@mail.buct.edu.cn). 
In this study, three bisphenol-A based epoxy resins with different size and structure of methylene, methine-phenyl and methine-naphthyl bridging groups were prepared to study the effect of structure of bridging groups on curing and properties of epoxy resins. For this purpose, the three epoxy resins were synthesized via condensation of bisphenol-A with formaldehyde, benzaldehyde, 1-naphthaldehyde, respectively, followed by epoxidation with excess epichlorohydrin. The curing kinetics of the synthesized epoxy resins toward 4,4'-diaminodiphenyl sulphone and the properties of the result polymer network such as thermal mechanical properties, thermal stability and moisture resistance were characterized by differential scanning calorimetry, dynamic mechanic analysis, thermogravimetric analysis, $\mathrm{X}$-ray diffraction and moisture resistance measurement.

\section{EXPERIMENTAL}

\section{Materials}

Epichlorohydrin (ECH), isopropanol, sodium hydroxide and methyl isobutyl ketone (MIBK) were analytical grade, obtained from Beijing Chemical Co., China, and were furtherly purified prior to use. Unless otherwise noted, all other reagents and chemicals were purchased from commercial suppliers and used without further purifications.

\section{Synthesis of Bisphenol-A Based Novolac Resins ${ }^{25-27}$}

A typical preparation was as follows. A $200 \mathrm{~mL}$ methyl isobutyl ketone (MIBK) solution containing $68.4 \mathrm{~g}$ bisphenol-A (BPA, $0.3 \mathrm{~mol}$ ) and $1.43 \mathrm{~g} p$-toluene sulfonic acid (PTSA, $0.0075 \mathrm{~mol}$ ) was added to $500 \mathrm{~mL}$ four-neck round-bottom flask, equipped with a heating mantle, mechanical stirrer, thermocouple, temperature controller, and a Dean-Stark trap with a reflux condenser. After purging with nitrogen for $10 \mathrm{~min}$, the solution was heated to $100^{\circ} \mathrm{C}$ with stirring. A $0.2 \mathrm{~mol} 1$-naphthaldehyde was added dropwise to the solution for about $1 \mathrm{~h}$. Subsequently, the temperature of the flask was kept at $120^{\circ} \mathrm{C}$ for $5 \mathrm{~h}$ allowing the reaction to occur. Water generated during the reaction was removed via azeotropic distillation with MIBK. The condensing of preparing bisphenol-A based novolac resin is reversible, for this reason, the azeotropic distillation method was exclusively utilized in this work.

Subsequently, the above solution was washed with deionized water until it became neutral. The solution was finally evaporated at $180^{\circ} \mathrm{C}$ under reduced pressure to remove the unreacted 1-naphthaldehyde and solvent. The remained solid product was washed with a mixture of water/methanol (68/32 v/v) several times to remove the unreacted BPA. A red brown solid product was obtained after vacuum-drying which was denoted as $I_{c}$.

Bisphenol-A-formaldehyde novolac resin and bisphenol-A-benzaldehyde novolac resin were synthesized according to the method for synthesis of $I_{c}$ and were denoted as $I_{a}$ and $I_{b}$, respectively. Figure 1 shows the syntheses of bisphenol-A based novolac resins $\left(I_{a}, I_{b}\right.$ and $\left.I_{c}\right)$.

Synthesis of Bisphenol-A Based Novolac Epoxy Resins

A typical preparation was as follows. A 0.15 equivalent of the above synthesized novolac resin based on bisphenol $\mathrm{A}\left(\mathrm{I}_{\mathrm{c}}\right)$ and $3 \mathrm{~mol}$ of epichlorohydrin $(\mathrm{ECH})$, $50 \mathrm{~g}$ of isopropanol (IPA) were added to a $500 \mathrm{~mL}$ four-neck round-bottom flask. After thoroughly mixed at room temperature, the mixture was heated to $70^{\circ} \mathrm{C}$. Subsequently, $32 \mathrm{~g}$ of $20 \mathrm{wt} \%$ aqueous sodium hydroxide solution was introduced dropwise to the solution with stirring over $1 \mathrm{~h}$. The system was maintained at $70^{\circ} \mathrm{C}$ for additional $4 \mathrm{~h}$, and the bottom brine layer was removed by siphoning. The remaining was further reacted with $20 \mathrm{wt} \%$ aqueous $\mathrm{NaOH} 16 \mathrm{~g}$ at $70^{\circ} \mathrm{C}$ for $1 \mathrm{~h}$. Finally, the product in the flask was washed several times with deionized water to remove the residual sodium chloride, and the excess ECH was thereafter evaporated under a reduced pressure to obtain a light brown-colored solid product denoted as $\mathrm{II}_{\mathrm{c}}$. The corresponding epoxy resins $\mathrm{II}_{\mathrm{a}}$ and $\mathrm{II}_{\mathrm{b}}$ were obtained from resins $I_{a}$ and $I_{b}$, respectively. Figure 2 shows the syntheses of bisphenol-A based novolac epoxy resins $\left(\mathrm{II}_{\mathrm{a}}\right.$, $\mathrm{II}_{\mathrm{b}}$, and $\mathrm{II}_{\mathrm{c}}$ ).

\section{Curing of Bisphenol-A Based Novolac Epoxy Resins}

A mixture of bisphenol-A based novolac epoxy resin $5 \mathrm{~g}$ and curing agents (DDS) in a molar ratio of $1: 1$ were dissolved in $40 \mathrm{~mL}$ acetone at room temperature and then acetone was evaporated under vacuum. The cured epoxy resins were obtained by mixing the reactant compositions homogeneously at $120^{\circ} \mathrm{C}$, and subsequently cured at $160^{\circ} \mathrm{C}$ for $2 \mathrm{~h}$, followed by curing at $200^{\circ} \mathrm{C}$ for $10 \mathrm{~h}$, finally postcured at $220^{\circ} \mathrm{C}$ for $2 \mathrm{~h}$.

\section{Characterization}

FT-IR spectra were recorded using a Nexus 670 infrared spectrometer in the range of $4000-400 \mathrm{~cm}^{-1}$ on the $\mathrm{KBr}$ pellets.

With deuterated acetone solvent, ${ }^{1} \mathrm{H}$ nuclear magnetic resonance $\left({ }^{1} \mathrm{H}\right.$ NMR) spectra were recorded on a Bruker AV-600 NMR, and tetramethylsilane was used as the internal standard. The operating parameters for ${ }^{1} \mathrm{H}$ NMR were as follows: sweep width: $600 \mathrm{MHz}$; pulse width: $5.80 \mu \mathrm{s}$; number of scans: 16 .

Gel permeation chromatography (GPC) was performed using PE series 200 equipped with polystyrene 


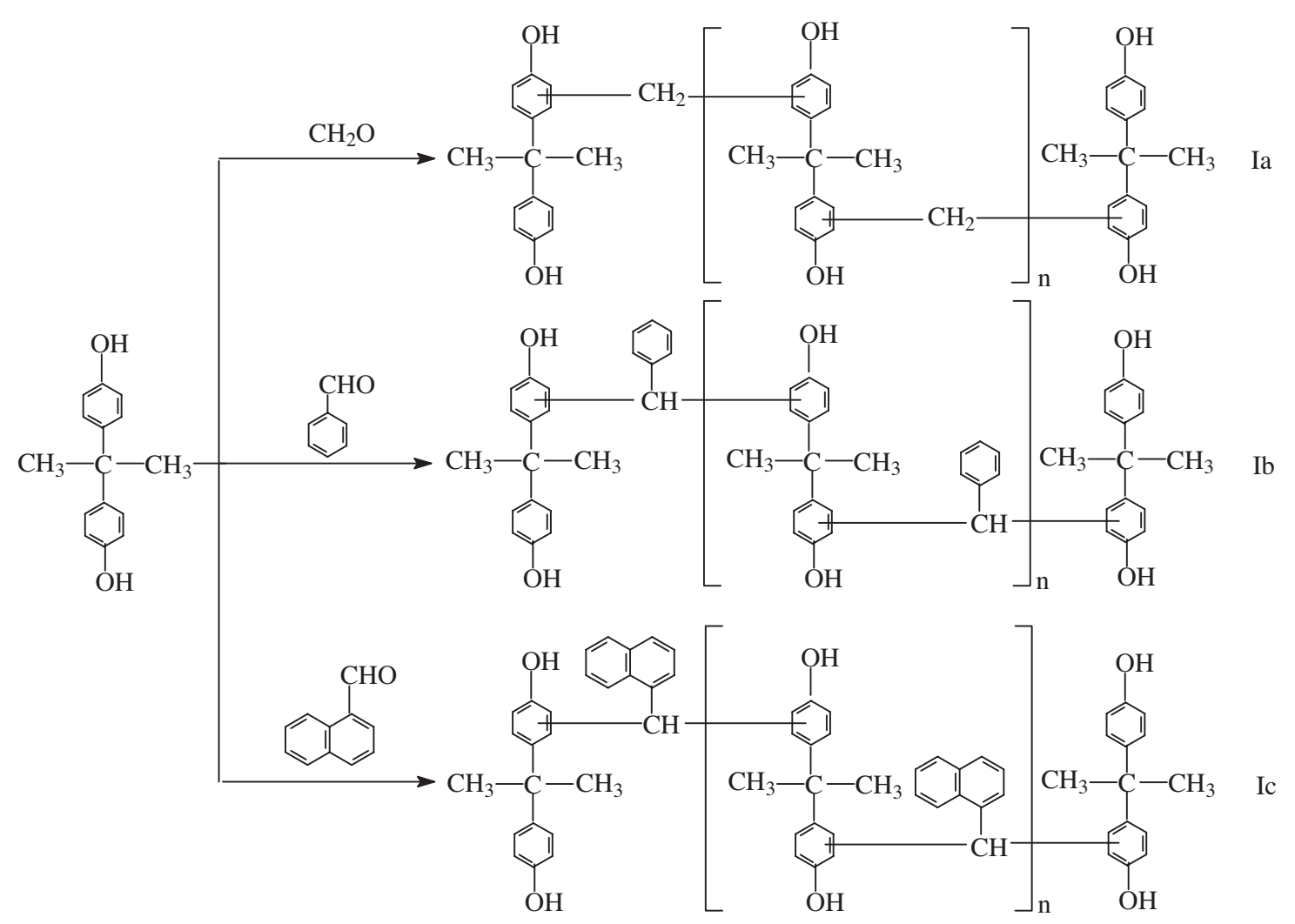

Figure 1. Syntheses of bisphenol-A based novolac resins. (The mole ratio between bisphenol-A and formaldehyde, benzaldehyde, naphthaldehyde was $3: 2$ ).

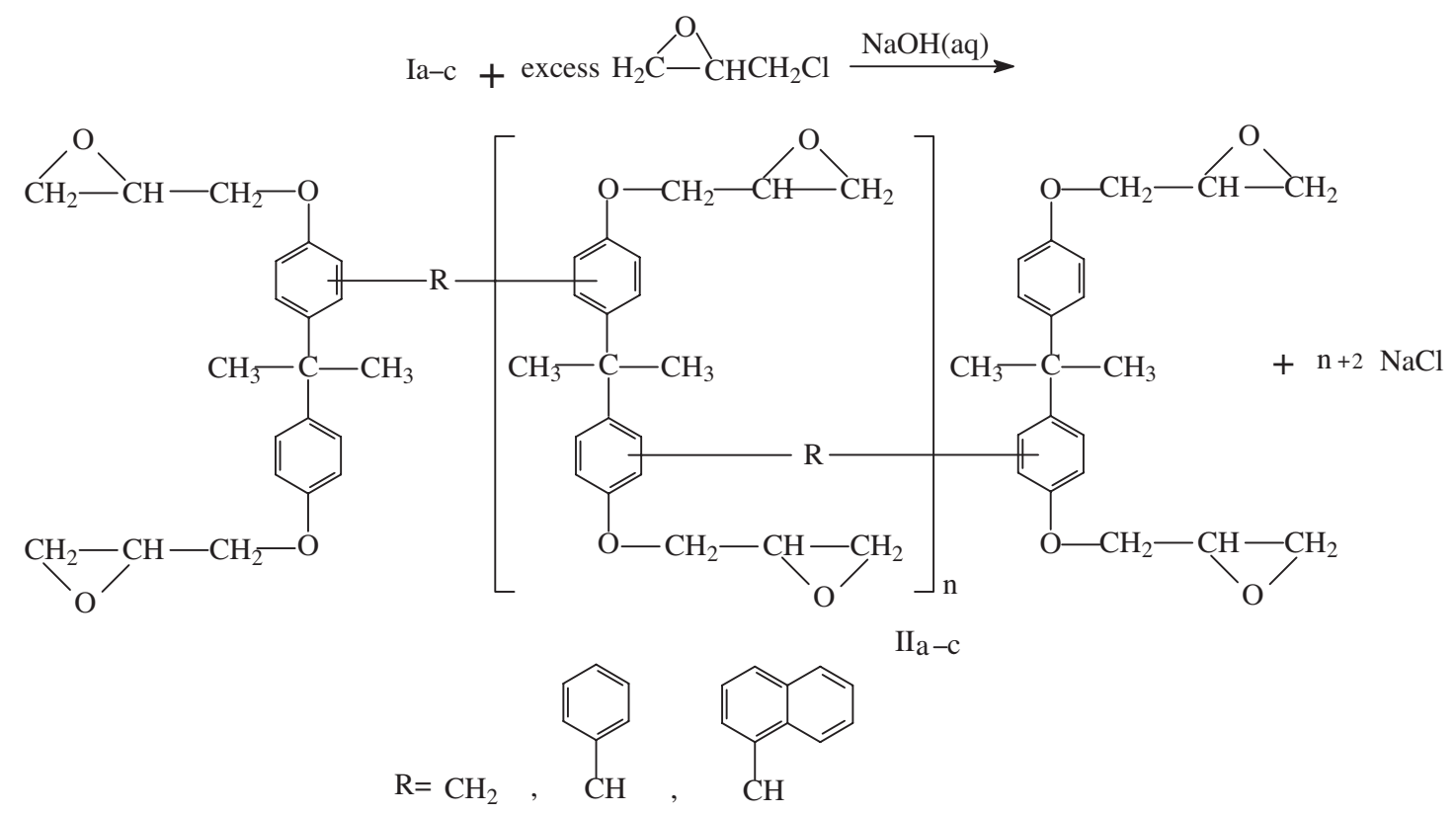

Figure 2. Syntheses of bisphenol-A based novolac epoxy resins.

gel columns and a UV detector at $30^{\circ} \mathrm{C}$ at $1 \mathrm{~mL} / \mathrm{min}$ flow rate.

The epoxy equivalent weights (EEWs) of epoxy resin were determined by the hydrochloric acid-acetone titration.

Differential scanning calorimetry (DSC) were per- formed using a Shimadzu DSC-41 differential scanning calorimeter by dynamic temperature scan experiments at $5,10,15$ and $20^{\circ} \mathrm{C} / \mathrm{min}$ in nitrogen flow.

Dynamic viscoelastic properties were measured using an American Rheometric Scientific DMTA-V thermal analysis system, with DMA mode between 
Table I. Average molecular weights and molecular polydispersity index (PID) of bisphenol-A based novolac resins and novolac epoxy resins and their EEWs

\begin{tabular}{lcccc}
\hline Sample code & $M_{\mathrm{n}}$ & $M_{\mathrm{w}}$ & PID $\left(M_{\mathrm{w}} / M_{\mathrm{n}}\right)$ & EEW \\
\hline $\mathrm{I}_{\mathrm{a}}$ & 750 & 1340 & 1.79 & - \\
$\mathrm{II}_{\mathrm{a}}$ & 890 & 1770 & 1.99 & 200 \\
$\mathrm{I}_{\mathrm{b}}$ & 780 & 1690 & 2.17 & - \\
$\mathrm{II}_{\mathrm{b}}$ & 950 & 2110 & 2.22 & 238 \\
$\mathrm{I}_{\mathrm{c}}$ & 810 & 1570 & 1.94 & - \\
$\mathrm{II}_{\mathrm{c}}$ & 960 & 2220 & 2.31 & 263 \\
\hline
\end{tabular}

$50{ }^{\circ} \mathrm{C}$ and $300^{\circ} \mathrm{C}$, with a heating rate of $5^{\circ} \mathrm{C} / \mathrm{min}$ at a frequency of $1 \mathrm{~Hz}$ under nitrogen atmosphere. The temperature/time scan in a three-point bending mode was chosen and the dimension of the specimen was $30 \mathrm{~mm} \times 5 \mathrm{~mm} \times 2 \mathrm{~mm}$ to determine the elastic modulus $\left(E^{\prime}\right)$ and mechanical loss factor $(\tan \delta)$.

The thermogravimetric analysis (TGA) was performed by simultaneous analyzer NETZSCH STA 449C TG-DSC at a heating rate of $10^{\circ} \mathrm{C} / \mathrm{min}$ under nitrogen atmosphere at $10 \mathrm{~mL} / \mathrm{min}$.

Wide-angle X-ray diffraction patterns (WAXD) were obtained uisng a diffractometer Rigaku D/max2400 at room temperature using copper filtered $\mathrm{Cu} \mathrm{K} \alpha$ radiation $(40 \mathrm{KV}, 200 \mathrm{~mA})$.

The moisture absorption was determined by placing preweighed $1 \mathrm{~mm}$ thick $\times 50 \mathrm{~mm}$ diameter cured disks in boiling water for $72 \mathrm{~h}$ to determine the weight gaining.

\section{RESULTS AND DISCUSSION}

Characterization of Bisphenol-A Based Novolac Resins and Epoxy Resins

Average molecular weights for three type of bisphenol-A based navolac resins and epoxy resins were listed in Table I, molecular polydispersity index (PDI) and epoxy equivalent weights (EEWs) were also shown. The size of bridging groups increased, the EEWs of epoxy resins increased and thus the crosslinking density of corresponding cured epoxy resins decreased. The effect of EEWs on the properties of cured epoxy resins would be discussed later.

Figure 3(a)-(c) show the FT-IR spectra of bisphenol-A based novolac resins $\left(\mathrm{I}_{\mathrm{a}}, \mathrm{I}_{\mathrm{b}}\right.$, and $\mathrm{I}_{\mathrm{c}}$ ), respectively. For $I_{a}$, the reaction between BPA and formaldehyde was confirmed by the disappearance of the $\mathrm{C}=\mathrm{O}$ stretch absorption peak at $1640 \mathrm{~cm}^{-1}$, and the appearance of strong broad characteristic absorption peak of phenolic $\mathrm{OH}$ stretching vibration at 3342 $\mathrm{cm}^{-1}$ (trace a). In the case of $\mathrm{I}_{\mathrm{b}}$, the reaction between BPA and benzaldehyde was approved by the disappearance of the $\mathrm{C}=\mathrm{O}$ stretch absorption peak at $1702 \mathrm{~cm}^{-1}$, and the appearance of strong broad char-

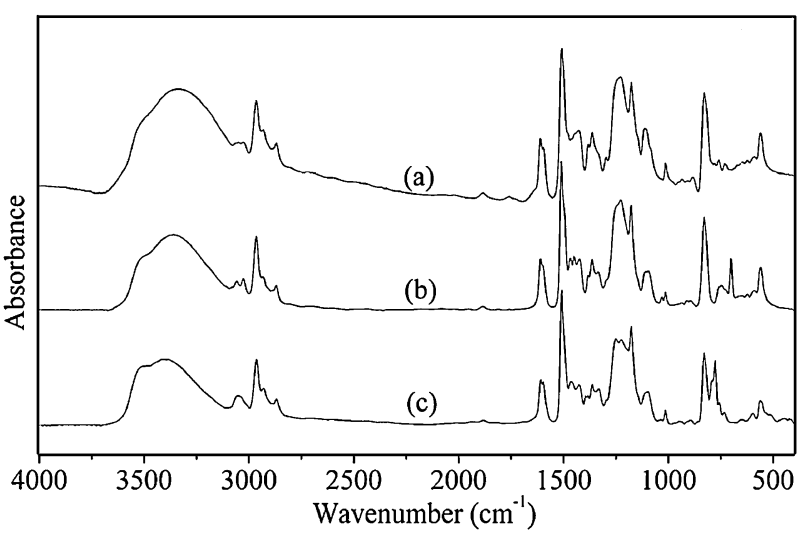

Figure 3. FT-IR spectra of bisphenol-A based novolac resins (a) $I_{a}$; (b) $I_{b}$ and (c) $I_{c}$.

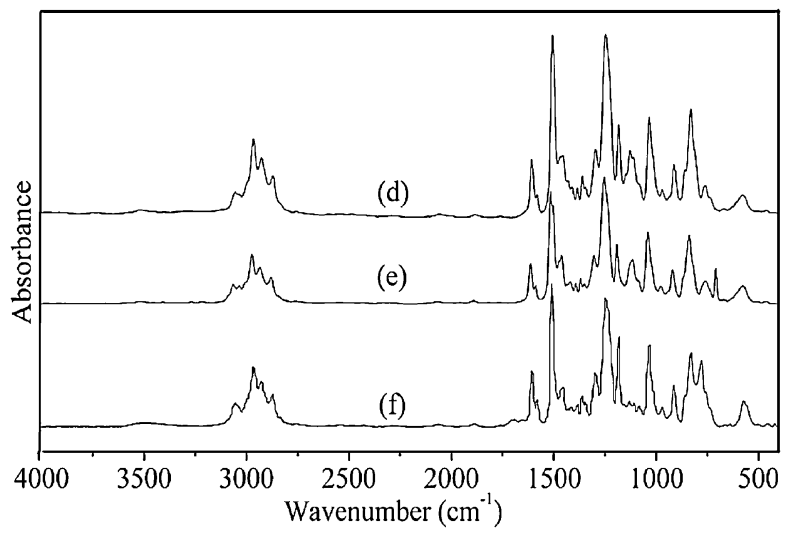

Figure 4. FT-IR spectra of bisphenol-A based novolac epoxy resins (d) $\mathrm{II}_{\mathrm{a}}$; (e) $\mathrm{II}_{\mathrm{b}}$ and (f) $\mathrm{II}_{\mathrm{c}}$.

acteristic absorption peak of phenolic $\mathrm{OH}$ stretching vibration at $3359 \mathrm{~cm}^{-1}$ (trace b). As far as $I_{c}$ was concerned, the reaction between BPA and 1-naphthaldehyde was characterized by the disappearance of the $\mathrm{C}=\mathrm{O}$ stretch absorption peak at $1689 \mathrm{~cm}^{-1}$, the appearance of characteristic absorption peak of $\alpha$-naphthalene out-of-plane deformation at $776 \mathrm{~cm}^{-1}$ and strong broad characteristic absorption peak of phenolic $\mathrm{OH}$ stretching vibration at $3406 \mathrm{~cm}^{-1}$ (trace c). In the spectra, the strong broad absorption bands in the region $3500-3200 \mathrm{~cm}^{-1}$ were assigned to the interand intra-molecular hydrogen band phenolic $\mathrm{OH}$ stretching vibration (Figure 3(a)-(c)). ${ }^{28}$

Figure 4(d)-(f) show the FT-IR spectra of biephenol A based novolac epoxy resins $\left(\mathrm{II}_{\mathrm{a}}, \mathrm{II}_{\mathrm{b}}\right.$, and $\left.\mathrm{II}_{\mathrm{c}}\right)$, respectively. The disappearance of broad phenolic $\mathrm{OH}$ stretching vibration bands in the region 3500$3200 \mathrm{~cm}^{-1}$ (Figure 3(a)-(c)) with the appearance of new strong bands at 840 and $914 \mathrm{~cm}^{-1}$ (Figure 4(d)(f)) due to the symmetrical and asymmetrical stretching modes of epoxy group, ${ }^{29}$ respectively, indicated the completion of etherification of phenolic hydroxyl.

Figure 5(a)-(c) show the ${ }^{1} \mathrm{H}$ NMR spectra of bi- 


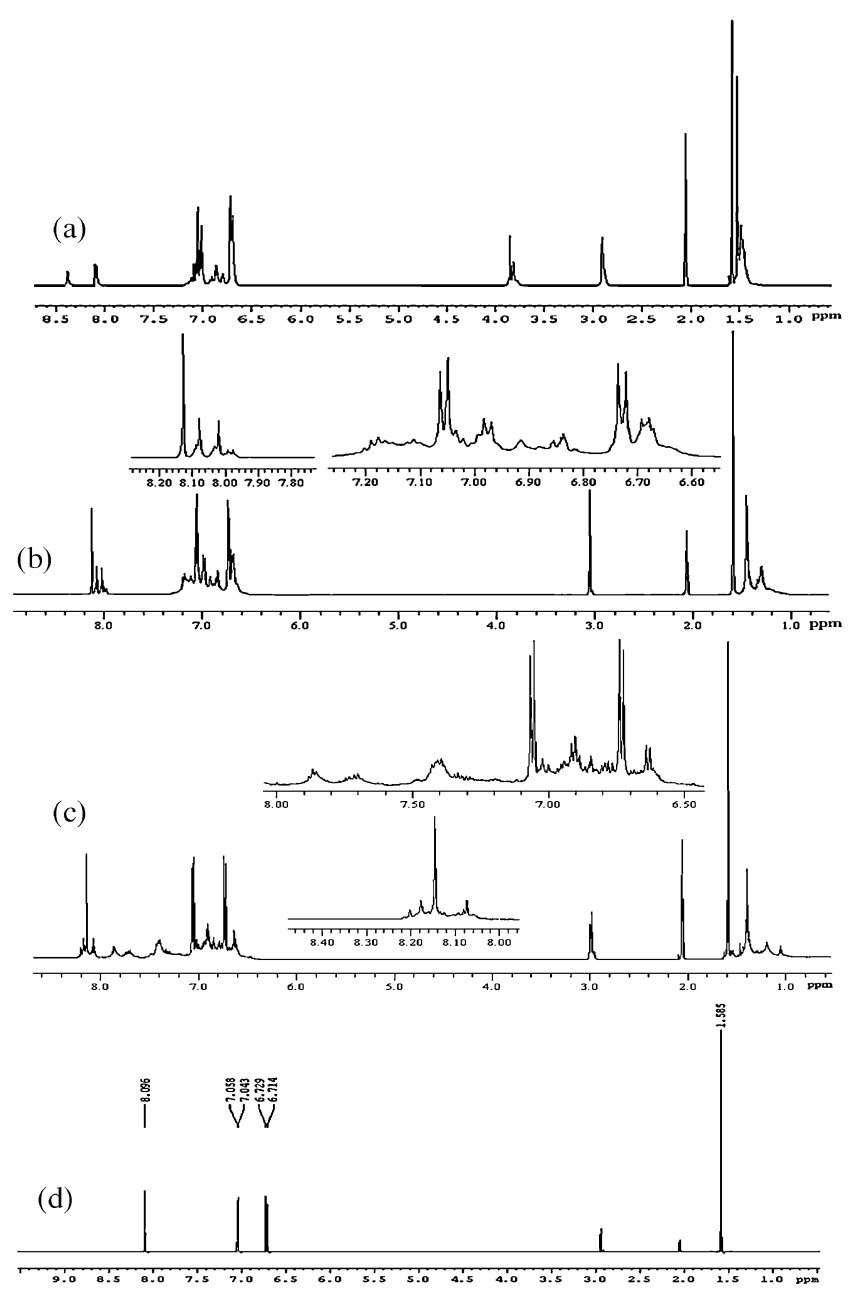

Figure 5. ${ }^{1} \mathrm{H}$ NMR spectra of (a) $I_{a}$, (b) $I_{b}$, (c) $I_{c}$ and (d) BPA in acetone- $d_{6}$.

sphenol-A based novolac epoxy resins $\left(\mathrm{I}_{\mathrm{a}}, \mathrm{I}_{\mathrm{b}}\right.$, and $\left.\mathrm{I}_{\mathrm{c}}\right)$ in acetone- $d_{6}$, respectively. For $\mathrm{I}_{\mathrm{a}}$, the multiplet peaks at $1.491-1.585 \mathrm{ppm}, 3.817-3.846 \mathrm{ppm}, 6.692-7.058$ ppm, and 8.081-8.684 ppm (Figure 5(a)) can be assigned to methyl, methylene bridges, aromatic, and hydroxyl protons, respectively. Concerning $\mathrm{I}_{\mathrm{b}}$, single peak at $1.595 \mathrm{ppm}$, multiplet peaks at $1.255-1.459$ ppm, 6.685-7.196 ppm, and 8.020-8.128 ppm (Figure 5(b)) can be attributed to methyl, methine bridges $\left(-\mathrm{CH}-\mathrm{C}_{6} \mathrm{H}_{5}\right)$, aromatic, and hydroxyl protons, respectively. For $\mathrm{I}_{\mathrm{c}}$, multiplet peaks at $1.202-1.411 \mathrm{ppm}$, $1.556-1.633 \mathrm{ppm}, 6.627-7.067 \mathrm{ppm}, 7.289-7.880 \mathrm{ppm}$, and $8.024-8.186 \mathrm{ppm}$ (Figure 5(c)) can be due to methine bridges $\left(-\mathrm{CH}-\mathrm{C}_{10} \mathrm{H}_{7}\right)$, methyl, aromatic $\left(-\mathrm{C}_{6} \mathrm{H}_{5}\right)$, aromatic $\left(-\mathrm{C}_{10} \mathrm{H}_{7}\right)$, and hydroxyl protons, respectively. Methylene, methine $\left(-\mathrm{CH}-\mathrm{C}_{6} \mathrm{H}_{5}\right)$, and methine $\left(-\mathrm{CH}-\mathrm{C}_{10} \mathrm{H}_{7}\right)$ bridges are the characteristic structures of $\mathrm{I}_{\mathrm{a}}, \mathrm{I}_{\mathrm{b}}$, and $\mathrm{I}_{\mathrm{c}}$, respectively, which can be obviously seen by comparing with the ${ }^{1} \mathrm{H}$ NMR spectrum of BPA (Figure 5(d)). In addition, two multiplet peaks corresponding to the aromatic protons on the phenol ring at $6.692-6.728 \mathrm{ppm}$ (ortho to the phe- nolic hydroxyl group) and 7.016-7.058 ppm (meta to the phenolic hydroxyl group) were observed symmetrical about a central point, this was because that BPA is a para-substituted aromatic compounds in which two substitutents differ from each other in electronic effects. However, compared with the ${ }^{1} \mathrm{H}$ NMR spectrum of BPA, the symmetrical patterns became complex and some split peaks appear between 6.728$7.016 \mathrm{ppm}$, which was assigned to the effect of the methylene, methine $\left(-\mathrm{CH}-\mathrm{C}_{6} \mathrm{H}_{5}\right)$, and methine $(-\mathrm{CH}-$ $\mathrm{C}_{10} \mathrm{H}_{7}$ ) bridges bonding to the BPA phenyl rings. In fact, the eight active positions on BPA for the methylene, methine $\left(-\mathrm{CH}-\mathrm{C}_{6} \mathrm{H}_{5}\right)$, and methine $\left(-\mathrm{CH}-\mathrm{C}_{10} \mathrm{H}_{7}\right)$ bridges to bond to the BPA phenyl rings can be categorized into two kinds, ortho and meta positions. The two kinds of positions appeared to possess the same bonding chance to the methylene, methine $(-\mathrm{CH}-$ $\left.\mathrm{C}_{6} \mathrm{H}_{5}\right)$, and methine $\left(-\mathrm{CH}-\mathrm{C}_{10} \mathrm{H}_{7}\right)$ bridges, which was indicated by the ratio of the peak areas for the two kinds of aromatic protons. Moreover, the ratios of area integrations for peaks ( $\mathrm{ph}-\mathrm{CH}_{2}-\mathrm{Ph} /$ aromatic protons $\left./ \mathrm{Ph}-\mathrm{C}-\mathrm{CH}_{3}\right)$ (Figure 5(a)), (ph- $\mathrm{CH}\left(-\mathrm{C}_{6} \mathrm{H}_{5}\right)-$ $\mathrm{Ph} /$ aromatic protons $/ \mathrm{Ph}-\mathrm{C}-\mathrm{CH}_{3}$ ) (Figure 5(b)), and (ph- $\mathrm{CH}\left(-\mathrm{C}_{10} \mathrm{H}_{7}\right)-\mathrm{Ph} /$ aromatic protons/ $\left.\mathrm{Ph}-\mathrm{C}-\mathrm{CH}_{3}\right)$ (Figure 5(c)) were consistent with the proposed statistical structures of $I_{a}, I_{b}$, and $I_{c}$, respectively, shown in Figure 1.

\section{Effect of the Structure of Epoxy Resins on Thermal Curing Reaction and Kinetics}

Figure 6(a)-(c) show the DSC traces of the cured epoxy resins of $\mathrm{II}_{\mathrm{a}}, \mathrm{II}_{\mathrm{b}}$, and $\mathrm{II}_{\mathrm{c}}$, respectively, with DDS. The temperature of the deviation from the baseline $\left(T_{\mathrm{i}}\right)$, the exotherm peak position $\left(T_{\mathrm{p}}\right)$, the temperature of completion of the exotherm $\left(T_{\mathrm{f}}\right)$, and the total reaction heat of curing $(\Delta H)$ were listed in Table II. The values of $T_{\mathrm{i}}, T_{\mathrm{p}}, T_{\mathrm{f}}$ and $\Delta H$ inecreased with increasing heating rate. The value of $T_{\mathrm{i}}$ depended on the reactivity of the epoxy resins toward DDS, and increasing in the order of $\mathrm{II}_{\mathrm{a}}<\mathrm{II}_{\mathrm{b}}<\mathrm{II}_{\mathrm{c}}$. The higher the value of $T_{\mathrm{i}}$, the lower the reactivity of epoxy resin, therefore, the reactivity of $\mathrm{II}_{\mathrm{c}}$ was lowest toward DDS.

In order to evaluate the curing reaction kinetic parameters, two multiple-heating-rate methods proposed by Flynn-Wall-Ozawa and that by Kissinger were used. $^{30-32}$ The above two methods assume that the exotherm peak temperature $\alpha_{p}$ was constant and was independent of the heating rate. ${ }^{33,34}$ This made the $n$th order and the autocatalytic reactions equally effective. For the Kissinger method, the maximum reaction rate occurs at peak temperatures, where $\mathrm{d}^{2} \alpha / \mathrm{d} t^{2}=0$, in this way, it can be expressed as

$$
\ln \left(\frac{\beta}{T_{\mathrm{p}}^{2}}\right)=\ln \left(\frac{A R}{E_{\mathrm{a}}}\right)-\frac{E_{\mathrm{a}}}{R T_{\mathrm{p}}}
$$



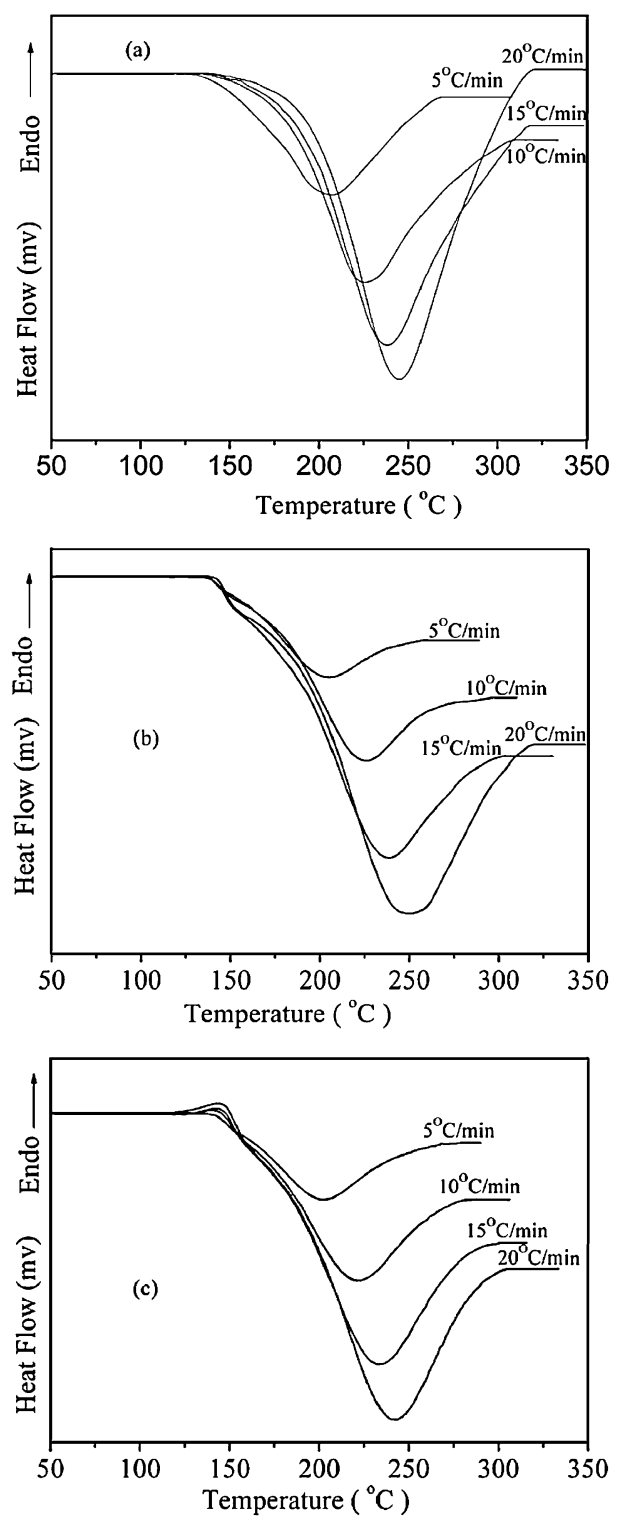

Figure 6. DSC thermograms for (a) $\mathrm{II}_{\mathrm{a}} / \mathrm{DDS}$, (b) $\mathrm{II}_{\mathrm{b}} / \mathrm{DDS}$ and $(c) \mathrm{II}_{\mathrm{c}} / \mathrm{DDS}$ systems at different heating rates.

where $T_{\mathrm{p}}$ is the exotherm peak temperature, $\beta$ is the linear heating rate, $A$ is the frequency factor, $E_{\mathrm{a}}$ is the activation energy and $R$ is the universal gas constant. Therefore, $E_{\mathrm{a}}$ can be obtained by plotting $\ln \left(\beta / T_{\mathrm{p}}^{2}\right)$ vs $T_{\mathrm{p}}^{-1}$, as displayed in Figure 7.

Based on eq 1 , the frequency factor $A$ can be obtained:

$$
A=\beta E_{\mathrm{a}} \exp \left(E_{\mathrm{a}} / R T_{\mathrm{p}}\right) / R T_{\mathrm{p}}^{2}
$$

The Flynn-Wall-Ozawa method yields a simple relationship between the activation energy, the heating rate, and iso-conversion temperature. It assumed that the degree of conversion at peak temperatures for different heating rates was constant, this giving the activation energy as:

$$
E_{\mathrm{a}}=-\frac{R}{0.4567} \frac{\mathrm{d} \log \beta}{\mathrm{d}\left(1 / T_{\mathrm{i}}\right)}=-\frac{R}{1.052} \frac{\mathrm{d} \ln \beta}{\mathrm{d}\left(1 / T_{\mathrm{i}}\right)}
$$

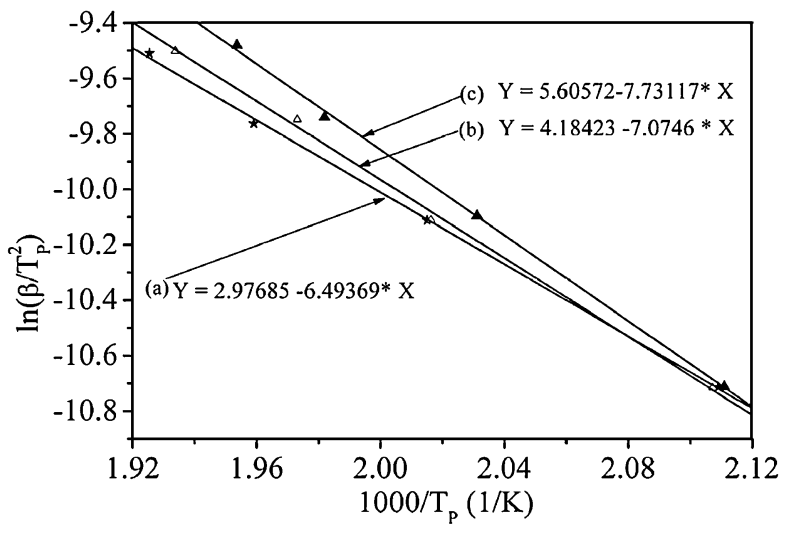

Figure 7. Plots for determination the activation energy of the curing reaction by Kissinger method: (a) $\mathrm{II}_{\mathrm{a}} / \mathrm{DDS}$; (b) $\mathrm{II}_{\mathrm{b}} / \mathrm{DDS}$ and (c) $\mathrm{II}_{\mathrm{c}} / \mathrm{DDS}$.

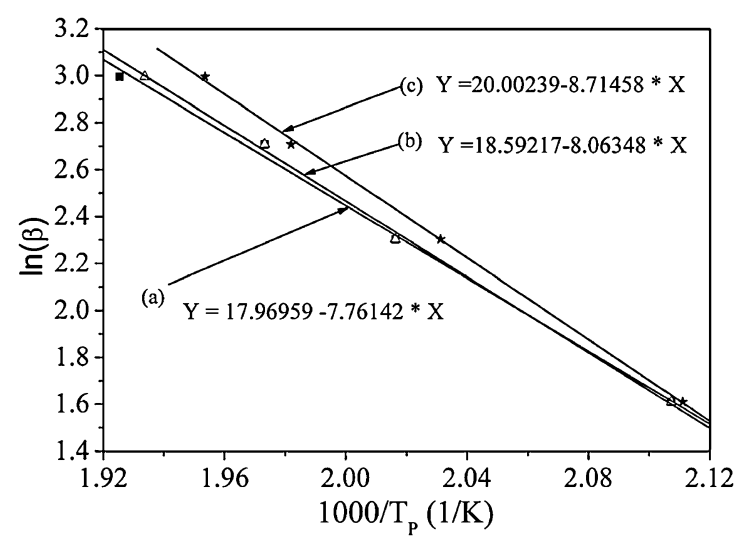

Figure 8. Plots for determination the activation energy of the curing reaction by Ozawa method: (a) $\mathrm{II}_{\mathrm{a}} / \mathrm{DDS}$; (b) $\mathrm{II}_{\mathrm{b}} / \mathrm{DDS}$ and (c) $\mathrm{II}_{\mathrm{c}} / \mathrm{DDS}$.

$$
=-\frac{R}{1.052} \frac{\mathrm{d} \ln \beta}{\mathrm{d}\left(1 / T_{\mathrm{p}}\right)}
$$

where $T_{\mathrm{i}}$ is the iso-conversion temperature and other parameters are the same as described above. Plotting $\ln \beta$ vs. $1 / T_{\mathrm{p}}$, as shown in Figure 8, the activation energy can be obtained from the slope. The advantage here is that the activation energy can be measured over the entire course of the reaction.

All the dynamic cure parameters of various epoxy systems calculated from above equations are summarized in Table II. One may notice that although the activation energy values obtained from the two models are different, they are in the order of $\mathrm{II}_{\mathrm{a}} / \mathrm{DDS}<\mathrm{II}_{\mathrm{b}} /$ $\mathrm{DDS}<\mathrm{II}_{\mathrm{c}} / \mathrm{DDS}$, consistent with that for the reactivity. The values of $A$, which account for the differences in stereo, electronics, collision factors is also in the order as activation energy: $\mathrm{II}_{\mathrm{a}}>\mathrm{II}_{\mathrm{b}}>\mathrm{II}_{\mathrm{c}}$.

This result may be attributed to difference of the steric hindrance of the bridging group in $\mathrm{II}_{\mathrm{a}}, \mathrm{II}_{\mathrm{b}}$ and $\mathrm{II}_{\mathrm{c}}$. For $\mathrm{II}_{\mathrm{c}}$, the methane-naphthyl linkage which pos- 
G. PAN et al.

Table II. Curing characteristics of the samples evaluated with DSC thermograms

\begin{tabular}{|c|c|c|c|c|c|c|c|c|}
\hline \multirow{2}{*}{$\begin{array}{l}\text { Sample } \\
\text { code }\end{array}$} & \multirow{2}{*}{$\begin{array}{c}\text { Heating rate } \\
\left({ }^{\circ} \mathrm{C} / \mathrm{min}\right)\end{array}$} & \multirow{2}{*}{$\begin{array}{c}T_{\mathrm{i}} \\
\left({ }^{\circ} \mathrm{C}\right)\end{array}$} & \multirow{2}{*}{$\begin{array}{c}T_{\mathrm{p}} \\
\left({ }^{\circ} \mathrm{C}\right)\end{array}$} & \multirow{2}{*}{$\begin{array}{c}T_{\mathrm{f}} \\
\left({ }^{\circ} \mathrm{C}\right) \\
\end{array}$} & \multirow{2}{*}{$\begin{array}{c}\Delta H \\
(\mathrm{~J} / \mathrm{g})\end{array}$} & \multicolumn{2}{|c|}{$E_{\mathrm{a}}(\mathrm{KJ} / \mathrm{mol})$} & \multirow{2}{*}{$\begin{array}{l}\ln (A) \\
\min ^{-1}\end{array}$} \\
\hline & & & & & & Kissinger & Ozawa & \\
\hline \multirow{4}{*}{$\mathrm{II}_{\mathrm{a}} / \mathrm{DDS}$} & 5 & 116.5 & 201.2 & 276.9 & 176.3 & \multirow{4}{*}{54.83} & \multirow{4}{*}{61.34} & 11.99 \\
\hline & 10 & 119.8 & 223.3 & 307.2 & 265.9 & & & 11.97 \\
\hline & 15 & 123.5 & 237.5 & 319.8 & 284.4 & & & 11.95 \\
\hline & 20 & 127.8 & 246.4 & 321.0 & 290.5 & & & 11.98 \\
\hline \multirow{4}{*}{$\mathrm{II}_{\mathrm{b}} / \mathrm{DDS}$} & 5 & 136.3 & 201.6 & 258.1 & 151.9 & \multirow{4}{*}{58.82} & \multirow{4}{*}{63.73} & 13.06 \\
\hline & 10 & 139.7 & 223.0 & 296.7 & 154.9 & & & 13.02 \\
\hline & 15 & 140.6 & 233.8 & 301.0 & 160.3 & & & 13.07 \\
\hline & 20 & 141.0 & 244.1 & 319.8 & 186.1 & & & 13.04 \\
\hline \multirow{4}{*}{$\mathrm{II}_{\mathrm{c}} / \mathrm{DDS}$} & 5 & 137.5 & 200.7 & 278.6 & 198.4 & \multirow{4}{*}{64.28} & \multirow{4}{*}{68.87} & 14.56 \\
\hline & 10 & 141.9 & 219.3 & 294.9 & 201.4 & & & 14.56 \\
\hline & 15 & 144.3 & 231.6 & 300.3 & 203.9 & & & 14.54 \\
\hline & 20 & 144.7 & 238.9 & 311.6 & 210.0 & & & 14.58 \\
\hline
\end{tabular}

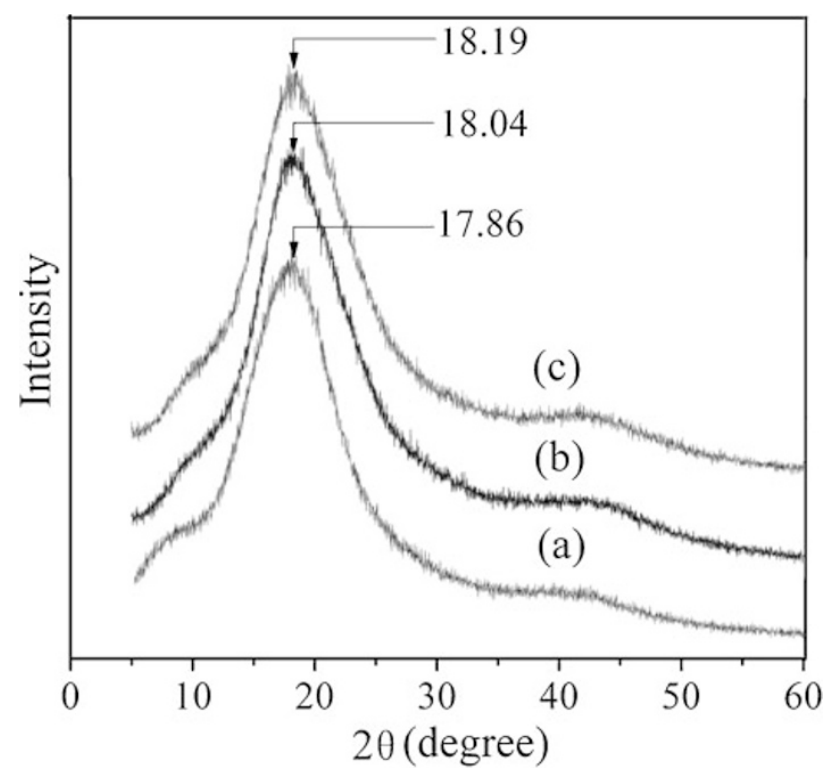

Figure 9. WAXD patterns for cured systems of (a) $\mathrm{II}_{\mathrm{a}} / \mathrm{DDS}$; (b) $\mathrm{II}_{\mathrm{b}} / \mathrm{DDS}$ and (c) $\mathrm{II}_{\mathrm{c}} / \mathrm{DDS}$.

sessed the lowest flexibility and largest size reduced the molecular mobility and depressed the reactivity of reactive site to the greatest extent. The reactions between the bridging groups and DDS are mainly the addition of amine to the epoxy group, which are generally related to the steric, inductive and resonance nature of monomer structure. In the precursors $\mathrm{II}_{\mathrm{a}}$, $\mathrm{II}_{\mathrm{b}}$ and $\mathrm{II}_{\mathrm{c}}$, the reactive sites are separated by almost the same distance, however, the EEW of $\mathrm{II}_{\mathrm{c}}$ is the highest, as a consequence, its functional group spatial density is the lowest and the molecules appear to be the most immobile during reaction.

\section{Wide-Angle X-Ray Diffraction Patterns}

Figure 9 shows the room temperature wide-angle $\mathrm{X}$-ray diffraction diagrams for cured systems of $\mathrm{II}_{\mathrm{a}} /$ DDS, $\mathrm{II}_{b} / \mathrm{DDS}$, and $\mathrm{II}_{\mathrm{c}} / \mathrm{DDS}$. The absence of noticeable diffractions primarily indicated that the cured systems were amorphous. However, the difference in the center of the three broad arches suggested that the packing was somewhat different for three systems. Calculated from the location of the peaks, the average inter-segment distance in $\mathrm{II}_{\mathrm{a}} / \mathrm{DDS}, \mathrm{II}_{\mathrm{b}} / \mathrm{DDS}$, and $\mathrm{II}_{\mathrm{c}} /$ DDS systems was $5.02 \AA, 4.91 \AA$, and $4.87 \AA$, respectively, which suggested that the last system was most densely compacted.

\section{Effect of the Structure of Epoxy Resins on Cured Res-} ins Mechanical and Thermal Properties

Figure 10(a) and (b) show the dependence of storage modulus $\left(E^{\prime} s\right)$ and $\tan \delta$ of the cured systems, respectively. The methine-naphthyl-bridged epoxy network possessed highest $E^{\prime}$ in glassy region, and the methine-phenyl-bridged epoxy network being the second. There were mainly two factors which controlled the $E^{\prime}$ s of the epoxy networks. One was the crosslinking density of epoxy networks, the other was the size of bridging groups. One can find from Table I, the EEWs of the epoxy resins increase in the order of $\mathrm{II}_{\mathrm{a}}<\mathrm{II}_{\mathrm{b}}<\mathrm{II}_{\mathrm{c}}$, the higher the EEW, the lower the crosslinking density of the epoxy network. An decrease of the crosslinking density can increase the chain mobility and, consequently, decreases the values of the $E^{\prime} \mathrm{s} .{ }^{35} \mathrm{In}$ the other hand, the size of the bridging groups increase in the order of $\mathrm{II}_{\mathrm{a}}<\mathrm{II}_{\mathrm{b}}<\mathrm{II}_{\mathrm{c}}$. On above discussion, an increase in the size of the bridging groups between two bridging points can increase the average inter-segment distance, thus increase the steric hindrance, as a result, lower the movement of the molecular chain and increase the values of the $E^{\prime}$ s. The results indicated that the effect of size of bridging groups on the chain mobility prevailed over that of the crosslinking density. Therefore, the $E^{\prime}$ s of epoxy network can be elevated drastically by the introducing some bulky rigid group into the backbone of monomer.

The glass transition temperature was indicated by 

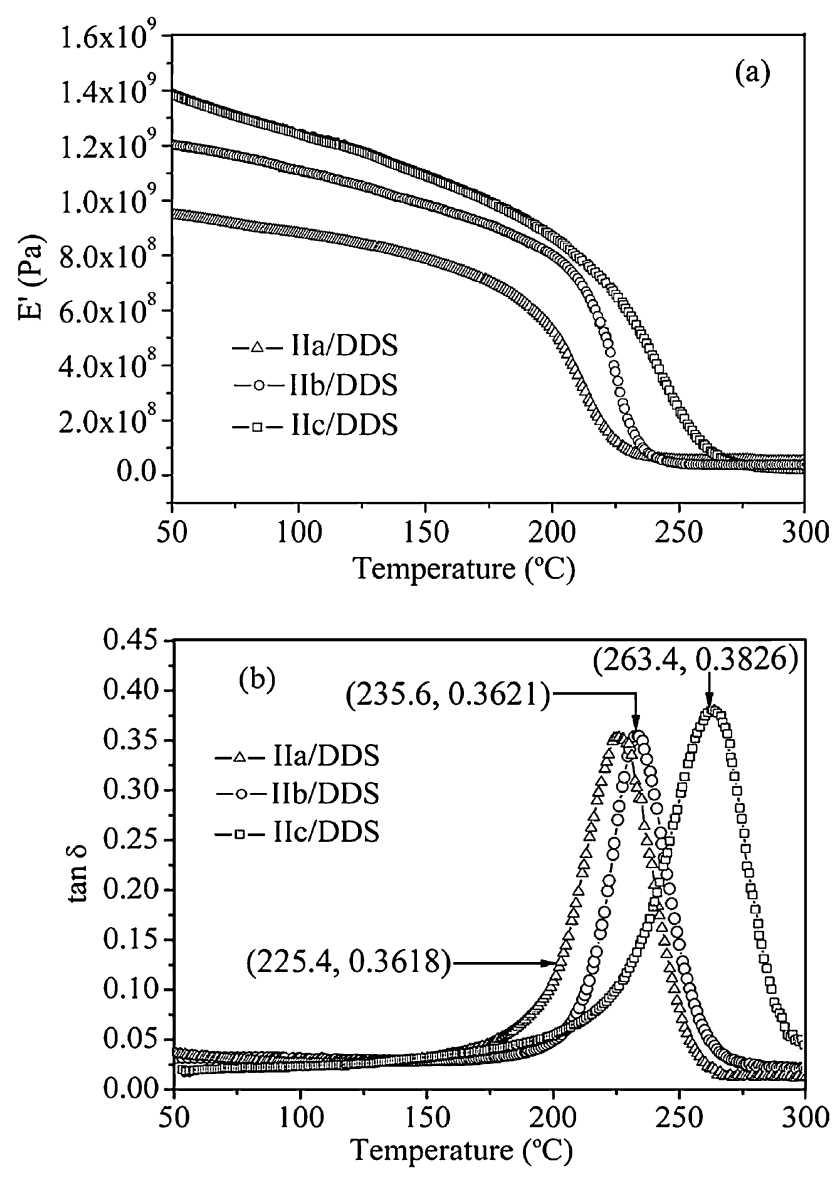

Figure 10. Temperature dependences of (a) storage modulus $E^{\prime}$ and (b) $\tan \delta$ for cured $\mathrm{II}_{\mathrm{a}} / \mathrm{DDS}, \mathrm{II}_{\mathrm{b}} / \mathrm{DDS}$ and $\mathrm{II}_{\mathrm{c}} / \mathrm{DDS}$.

the peak of $\tan \delta$. Again, one may notice that the methine-naphthyl-bridged and methine-phenyl-bridged epoxy networks exhibited higher $T_{\mathrm{g}} \mathrm{s}$ than that of methylene-bridged epoxy network. This may result from the rigidity imparted by the methine-naphthy and methane-phenyl groups to the crosslinked network, which restrained the movements of the polymer segments, and revealed that $T_{\mathrm{g}}$ was influenced more strongly by the backbone rigidity of epoxy, i.e., was affected more by molecular mobility than by crosslinking density, therefore, it is possible to design epoxy systems that exhibit high $T_{\mathrm{g}}$, high modulus.

Figure 11 presents the TGA and DTG traces of the cured systems: (a) $\mathrm{II}_{\mathrm{a}} / \mathrm{DDS}$; (b) $\mathrm{II}_{\mathrm{b}} / \mathrm{DDS}$ and (c) $\mathrm{II}_{\mathrm{c}} /$ DDS under nitrogen atmosphere, and the TGA data for various polymers are collected in Table III. As depicted in Table III, by comparing the $T_{5}, T_{10}$ and $T_{\max }$, one can find that $\mathrm{II}_{\mathrm{b}}$ and $\mathrm{II}_{\mathrm{c}}$ networks demonstrated better resistance to thermally degradation than $\mathrm{II}_{\mathrm{a}}$ network. This result probably related to the introduction of more thermal resistance aromatic bridging groups. The percent char yield for cured systems at $600^{\circ} \mathrm{C}$ and $800{ }^{\circ} \mathrm{C}$ decreased in the order of $\mathrm{II}_{c}>\mathrm{II}_{\mathrm{b}}>\mathrm{II}_{\mathrm{a}}$. This may be proposed that, for cured systems $\mathrm{II}_{\mathrm{b}} / \mathrm{DDS}$ and $\mathrm{II}_{\mathrm{c}} / \mathrm{DDS}$, because of the incorporation of aromatic
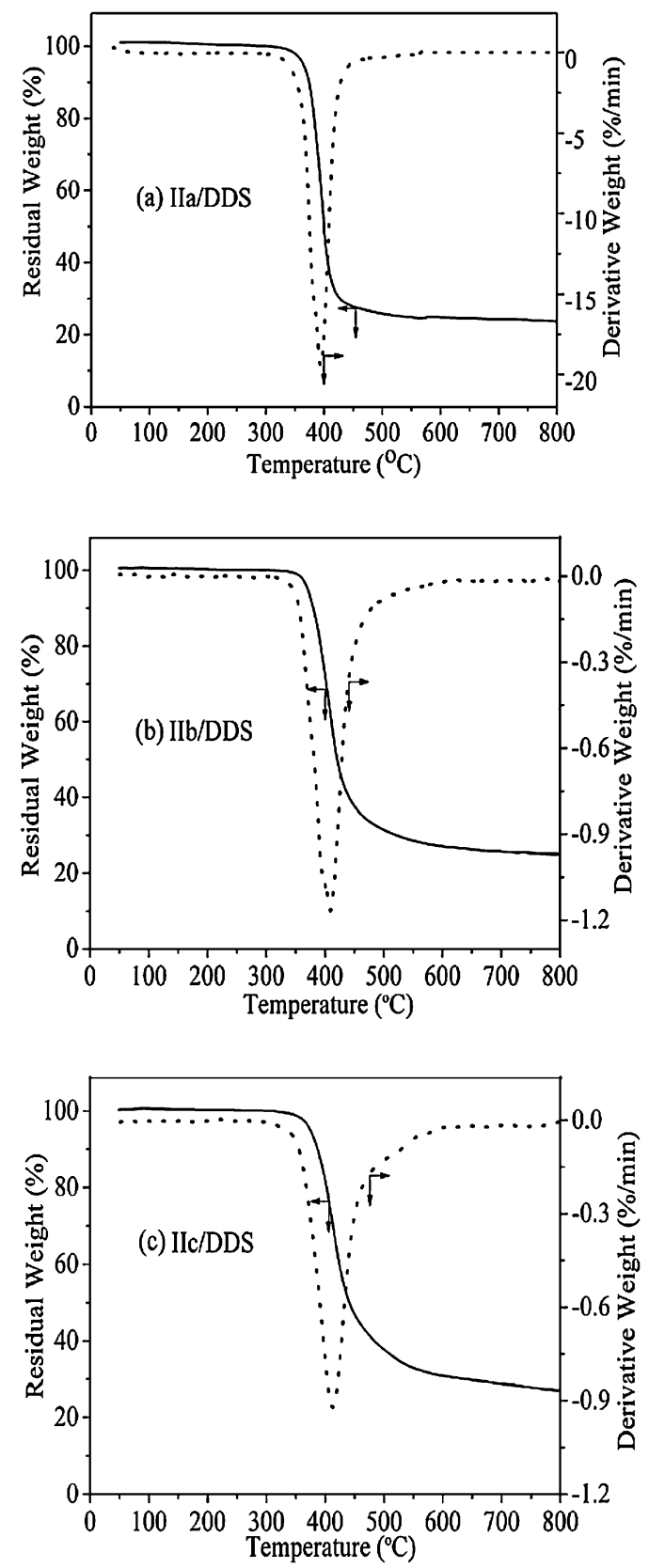

Figure 11. TGA and DTG traces for DDS cured epoxy polymers under nitrogen atmosphere.

Table III. Thermogravimetric analysis of cured polymers

\begin{tabular}{lccccc}
\hline $\begin{array}{l}\text { Sample } \\
\text { code }\end{array}$ & $\begin{array}{c}{ }^{\mathrm{a}} T_{5} \\
\left({ }^{\circ} \mathrm{C}\right)\end{array}$ & $\begin{array}{c}{ }^{\mathrm{b}} T_{10} \\
\left({ }^{\circ} \mathrm{C}\right)\end{array}$ & $\begin{array}{c}{ }^{\mathrm{c}} T_{\max } \\
\left({ }^{\circ} \mathrm{C}\right)\end{array}$ & $\begin{array}{c}\text { Char yield at } \\
600{ }^{\circ} \mathrm{C}(\%)\end{array}$ & $\begin{array}{c}\text { Char yield at } \\
800{ }^{\circ} \mathrm{C}(\%)\end{array}$ \\
\hline $\mathrm{II}_{\mathrm{a}} / \mathrm{DDS}$ & 355 & 374 & 397 & 24.82 & 23.67 \\
$\mathrm{II}_{\mathrm{b}} / \mathrm{DDS}$ & 370 & 380 & 409 & 27.03 & 24.97 \\
$\mathrm{II}_{\mathrm{c}} / \mathrm{DDS}$ & 375 & 387 & 412 & 30.88 & 27.10 \\
\hline
\end{tabular}

${ }^{\mathrm{a}} T_{5}$, temperature of $5 \%$ weight loss. ${ }^{\mathrm{b}} T_{10}$, temperature of $10 \%$ weight loss. ${ }^{\mathrm{c}} T_{\max }$, temperature of maximum rate of weight loss under nitrogen atmosphere. 
Table IV. Moisture absorption of cured epoxy resins

\begin{tabular}{lccccc}
\hline \multirow{2}{*}{$\begin{array}{l}\text { Sample } \\
\text { code }\end{array}$} & \multicolumn{5}{c}{ Water absorption gains (wt \%) } \\
\cline { 2 - 6 } & $12 \mathrm{~h}$ & $24 \mathrm{~h}$ & $36 \mathrm{~h}$ & $48 \mathrm{~h}$ & $72 \mathrm{~h}$ \\
\hline $\mathrm{II}_{\mathrm{a}} / \mathrm{DDS}$ & 1.547 & 2.129 & 2.258 & 2.336 & 2.427 \\
$\mathrm{II}_{\mathrm{b}} / \mathrm{DDS}$ & 1.521 & 2.072 & 2.157 & 2.287 & 2.365 \\
$\mathrm{II}_{\mathrm{c}} / \mathrm{DDS}$ & 1.474 & 2.045 & 2.123 & 2.268 & 2.308 \\
\hline
\end{tabular}

bridging groups, the formation of char is facilitated, and for the latter, the higher percent of aromatic moieties was introduced.

Effect of the Structure of Epoxy Resins on the Moisture Absorption of Cured Resins

In the practical using, absorbed moisture was found to plasticize the epoxy resin, ${ }^{36}$ causing a lowering of the $T_{\mathrm{g}}$ and in turn affecting mechanical properties, ${ }^{37-39}$ therefore, has attracted many studies. ${ }^{40-42}$ The moisture absorption measurement is shown in Table IV. It showed that all cured aromatic bridging group containing epoxy resins $\left(\mathrm{II}_{\mathrm{b}}\right.$ and $\mathrm{II}_{\mathrm{c}}$ ) had better moisture resistance than that of aliphatic bridging group containing epoxy resin $\left(\mathrm{II}_{\mathrm{a}}\right)$. The epoxy networks with aromatic bridging groups possessed smaller average inter-segment distance, indicated that they had smaller free volume, this can lead to a lower moisture absorption. Moreover, during the curing process, $-\mathrm{OH}$ groups were generated via ring opening of epoxy groups. ${ }^{43-46}$ With the EEW of epoxy resin increasing, the ring opening of epoxy reduced, thus less polar -OH groups were produced leading to a higher hydrophobicity of the cured system.

\section{CONCLUSIONS}

The effect of the bridging groups on the thermal curing behavior of bisphenol-A based epoxy resins with DDS was investigated, the activation energy value obtained from Kissinger and Ozawa method was fairly close and both in the trend $\mathrm{II}_{\mathrm{a}}<\mathrm{II}_{\mathrm{b}}<\mathrm{II}_{\mathrm{c}}$, the same with $\mathrm{A}$, this revealed that the steric hindrance of the epoxy resin systems in the order $\mathrm{II}_{\mathrm{a}}<\mathrm{II}_{\mathrm{b}}<\mathrm{II}_{\mathrm{c}}$, in other word, the bigger the size of bridging group, the higher the rigidity of epoxy resin. The methinenaphthyl-bridged epoxy network possessed the highest storage modulus, glass transition temperatures, thermal stability, and moisture resistance. These excellent overall performances for $\mathrm{II}_{\mathrm{c}}$ enable them a promising candidate to substitute $\mathrm{II}_{\mathrm{a}}$ in composite matrix and printed wiring boards, and integrated circuit encapsulations.

Acknowledgment. This work was supported by National Natural Science Foundation of China (No. 50503004).

\section{REFERENCES}

1. A. Igarashi, T. Terasawa, M. Kanie, T. Yamanobe, and T. Komoto, Polym. J., 37, 522 (2005).

2. C. B. Bucknall and A. H. Gillbert, Polymer, 30, 213 (1989).

3. C. S. Wang and M. C. Lee, Polymer, 41, 3631 (2000).

4. S. P. Rwei, C. Y. Cheng, G. S. Liou, and K. C. Cheng, Polym. Eng. Sci., 45, 478 (2005).

5. H. Okamura, K. Shin, and M. Shirai, Polym. J., 38, 1237 (2006).

6. C. S. Wang and M. C. Lee, J. Appl. Polym. Sci., 73, 1611 (1997).

7. A. Matsumoto, K. Hasegawa, and A. Fukuda, Polym. Int., 30, 65 (1993).

8. K. Ohta, W. Kosaka, and K. Yanagisawa, Eur. Patent 0428 871 A2 (1991).

9. C. S. Wang and M. C. Lee, J. Appl. Polym. Sci., 70, 1907 (1998).

10. C. P. Yang and W. T. Chen, J. Polym. Sci., Part A: Polym. Chem., 31, 2799 (1993).

11. J. Y. Lee and J. Jang, J. Polym. Sci., Part A: Polym. Chem., 37, 419 (1999).

12. C. S. Wang, T. S. Leu, and K. R. Hsu, Polymer, 39, 2921 (1998).

13. L. Callau, J. A. Reina, A. Mantecon, M. Tessier, and N. Spassky, Macromolecules, 32, 7790 (1999).

14. K. J. Patel, K. G. Amin, and R. G. Patel, J. Appl. Polym. Sci., 75, 1345 (2000).

15. K. Xu, M. C. Chen, K. Zhang, and J. W. Hu, Polymer, 45, 1133 (2004).

16. M. Kaji and T. Endo, J. Polym. Sci., Part A: Polym. Chem., 37, 3063 (1999).

17. T. H. Ho, Macromol. Mater. Eng., 283, 57 (2000).

18. Y. F. Duann, T. M. Liu, K. C. Cheng, and W. F. Su, Polym. Degrad. Stab., 8, 305 (2004).

19. R. J. Varley, J. H. Hodgkin, and G. P. Simon, J. Appl. Polym. Sci., 77, 237 (2000).

20. A. Chateauminois, V. Sauvant, and J. L. Halary, Polym. Int., 52, 507 (2003).

21. K. Xu, M. C. Chen, X. J. Zhang, and K. Zhang, Macromol. Chem. Phys., 205, 1559 (2004).

22. J. Y. Lee, J. Jang, S. M. Hong, S. S. Hwang, and K. U. Kim, Polymer, 40, 3197 (1999).

23. P. Jain, V. Choudhary, and I. K. Varma, Eur. Polym. J., 39, 181 (2003).

24. N. Gupta and I. K. Varma, J. Appl. Polym. Sci., 68, 1759 (1998).

25. C. Gouri, C. P. Reghunadhan Nair, and R. Ramaswamy, Polym. Int., 50, 403 (2001).

26. T. H. Ho and C. S. Wang, J. Appl. Polym. Sci., 74, 1905 (1999).

27. C. H. Lin, J. C. Chiang, and C. H. Wang, J. Appl. Polym. Sci., 88, 2607 (2003).

28. M. Ayman. N. O. Atta, N. E. Shaker, and Maysour, Prog. Org. Coat., 56, 100 (2006).

29. R. Arridge and J. Speake, Polymer, 13, 443 (1972).

30. T. Ozawa, J. Therm. Anal. Calorim., 2, 301 (1970).

31. J. H. Flynn and L. A. Wall, J. Appl. Polym. Sci., 4, 323 
(1966).

32. H. E. Kissinger, Anal. Chem., 29, 1702 (1957).

33. R. B. Prime, Polym. Eng. Sci., 13, 365 (1973).

34. M. C. Lu and J. L. Hong, Polymer, 35, 2822 (1994).

35. S. G. Allen, in "Comprehensive Polymer Sciences: the Synthesis, Characterization, Reactions and Applications of Polymers," C. Booth and C. Price, Ed., Pergamon Press, New York, 1989, Vol. 2, p 311.

36. M. C. Lee and N. A. Peppas, Prog. Polym. Sci., 18, 947 (1993).

37. E. L. Mckague, J. D. Reynolds, and J. E. Halkies, J. Appl. Polym. Sci., 22, 1643 (1978).

38. J. Mijovic and K. F. Lin, J. Appl. Polym. Sci., 30, 2527 (1985).

39. P. Musto, L. Mascia, G. Ragosta, G. Scarinzi, and P.
Villano, Polymer, 41, 565 (2000).

40. G. Z. Xiao and M. E. R. Shanahan, Polymer, 39, 3253 (1998).

41. E. Boinard, R. A. Pethrick, J. Dazel-Job, and C. J. Macfarlane, J. Mater. Sci., 35, 1931 (2000).

42. T. Kimura, Y. Nakamoto, and G. Konishi, Polym. J., 38, 606 (2006).

43. N. Sbirrazzuoli, A. Mititelu-Mija, V. Luc, and C. Alzina, Thermochim. Acta, 447, 167 (2006).

44. A. Catalani and M. G. Bonicelli, Thermochim. Acta, 438, 126 (2005).

45. S. Vyazovkin and N. Sbirrazzuoli, Macromolecules, 29, 1867 (1996).

46. S. Swier, G. V. Assche, W. Vuchelen, and V. M. Bruno, Macromolecules, 38, 2281 (2005). 